Review Article

\title{
Review on the Millimeter-Wave Generation Techniques Based on Photon Assisted for the RoF Network System
}

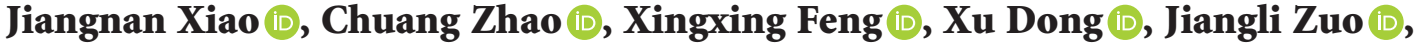 \\ Jun Ming $(\mathbb{D}$, and Ye Zhou
}

\begin{abstract}
Shanghai Key Lab of Modern Optical Systems, Terahertz Technology Innovation Research Institute and Engineering Research Center of Optical Instrument and System, Ministry of Education, University of Shanghai for Science and Technology, Shanghai 200093, China
\end{abstract}

Correspondence should be addressed to Jiangnan Xiao; jiangnanxiao@usst.edu.cn

Received 31 October 2020; Accepted 26 November 2020; Published 8 December 2020

Academic Editor: Junmin Liu

Copyright ( 92020 Jiangnan Xiao et al. This is an open access article distributed under the Creative Commons Attribution License, which permits unrestricted use, distribution, and reproduction in any medium, provided the original work is properly cited.

With the development trend of wireless and broadband in the communication link and even the whole information industry, the demand of high-frequency microwave bandwidth has been increasing. The RoF network system solves the problem of spectrum congestion in low-frequency band by providing an effective technology for the distribution of high-frequency microwave signals over optical fiber links. However, the traditional mm-wave generation technique is limited by the bandwidth of electronic devices. It is difficult to generate high-frequency and low-phase noise $\mathrm{mm}$-wave signals with pure electrical components. The mm-wave communication technology based on photon assisted can overcome the bandwidth bottleneck of electronic devices and provide the potential for developing the low-cost infrastructure demand of broadband mobile services. This paper will briefly explain the characteristics of the RoF network system and the advantages of high-frequency mm-wave. Then we, respectively, introduce the modulation schemes of RoF mm-wave generation based on photon assisted including directly modulated laser (DML), external modulation, and optical heterodyne. The review mainly focuses on a variety of different mm-wave generation technologies including multifrequency vector mm-wave. Furthermore, we list several approaches to realize the large capacity data transmission techniques and describe the digital signal processing (DSP) algorithm flow in the receiver. In the end, we summarize the RoF network system and look forward to the future.

\section{Introduction}

Facing the development of the ultrahigh definition (UHD) video streaming and the growth of mobile users on social media, people have increasingly higher requirements for communication capability and data transmission throughput. The rapid growth of data traffic is also augmenting the demand for broadband. Wired transmission network technology can provide huge bandwidth for Internet broadband users [1]. However, due to the limitation of an optical fiber or cable, the usability and generality of the products are cut down. Adopting high-speed wireless transmission can get rid of the shackles of fiber and greatly improve the comfort level of user experience [2]. In addition, due to the laying and cost of the line, operators and users prefer to allow roaming connections. Therefore, people try to combine the wired fiber transmission network with radio communication technology to propose the RoF network system $[2,3]$.

The RoF network system is a potential solution to increase the capacity and mobility of access networks and could also reduce the cost of access networks. And the current advanced mobile communication $5 \mathrm{G}$ and the future 6G technologies are all based on this technology [4]. The basic principle of RoF technology mainly consists of three parts: central stations (CSs), optical fiber, and base stations (BSs) [5]. The CS mainly use modulators to modulate radio frequency (RF) signals on light waves. After generating the $\mathrm{mm}$-wave, the signal is transmitted to the receiver or the BS through optical fibers. And then, the signal is transmitted to 
the user through the radio antenna. The RoF network system transmits data through optical fibers using radio signals to modulate optical information. This modulation can be performed directly with RF signals or intermediate frequency (IF) signals. The spectrum of radio signals currently allocated by RoF network systems is very wide usually gigahertz-depending on the application. So, any type of RF signal modulation schemes can be transmitted over optical fibers by the RoF network system theoretically $[5,6]$.

Furthermore, the application of the fiber-wireless integration (FWI) technology is not limited to this. In some special occasions (such as between islands), it is no picnic to lay the optical fiber, and the optical fiber link may be damaged accidentally. At this time, the integration of wireless technology and fiber communication can still play a huge role.

It is worth noting that the realization of the local area network (LAN) transmission rate up to Gbit/s is a big problem in the wireless communication network system $[6,7]$. The effective method is to increase the carrier frequency to extend the bandwidth of the wireless transmission network system [1]. But the available low-frequency spectrum is very tight. The distribution of its input scope is shown in Table 1.

It can be concluded from Table 1 that the frequency spectrum used by the wireless communication network system is mainly in the frequency band of $800 \mathrm{MHz} 30 \mathrm{GHz}$. Therefore, the available spectrum resources are already very limited which will seriously hinder the further development of mobile communication. If high-frequency mm-wave can be used as carrier signal, the obstacle of spectrum resource shortage could be overcome [9]. High-speed wireless broadband access is also possible, which makes the development of high-frequency regional spectrum more urgent [10].

In recent decades, the development and utilization of $\mathrm{mm}$-wave frequency band has become the main research hotspot of the RoF network system [11]. Such high-rate wireless networks can be as fast as or possibly faster than optical fibers. There are a lot of existing optical fibers or cables in large modern cities. High-frequency mm-wave can be transmitted in the existing prelaid optical fibers without the need to lay the optical fibers again which greatly cuts down the system cost.

The mm-wave refers to the microwave with a wavelength of $1 \mathrm{~mm} \sim 10 \mathrm{~mm}$, and the corresponding frequency range is $30 \mathrm{GHz} 300 \mathrm{GHz}$ [12]. For current wireless communication technologies, the $270 \mathrm{GHz}$ frequency range is a considerable and valuable resource. The most important point is that the $40 \mathrm{GHz} \sim 60 \mathrm{GHz}$ mm-wave signal can be used without authorization internationally [13]. Therefore, the research and application of the communication technology based on high-frequency mm-wave have been paid much attention in the world recently. The high-frequency mm-wave wireless communication network system has the following advantages:

(a) Millimeter-wave has very high frequency and large broadband, which can realize the transmission of
TABLE 1: Frequency range distribution table of the communication system [8].

\begin{tabular}{lc}
\hline Communication system & Frequency range \\
\hline Wi-Fi/Wi-MAX & $2.4 \mathrm{GHz}, 5 \sim 5.8 \mathrm{GHz}$ \\
GSM & $885 \sim 889 \mathrm{MHz}, 930 \sim 934 \mathrm{MHz}$ \\
CDMA & $825 \sim 835 \mathrm{MHz}, 870 \sim 880 \mathrm{MHz}$ \\
TD-SCDMA & $1785 \sim 1805 \mathrm{MHz}, 1800 \sim 1920 \mathrm{MHz}$ \\
LMDS & $26 \mathrm{GHz}$ \\
MM-CATV & $2.535 \sim 2.599 \mathrm{GHz}$ \\
SMC & $1.98 \sim 2.01 \mathrm{GHz}, 2.17 \sim 2.2 \mathrm{GHz}$ \\
\hline
\end{tabular}

data with superlarge capacity. Its information transfer rate can reach several hundred $\mathrm{GB} / \mathrm{s}$, up to $1 \mathrm{TGB} / \mathrm{s}$ [14].

(b) The BS and radio antennas of the wireless communication system using the mm-wave carrier technology are more miniaturized, which is very helpful for installation, maintenance, and function expansion

(c) The beam of mm-wave is very narrow and has good directivity in space propagation. Moreover, there are few interference sources in the propagation for the mm-wave in the high-frequency band. So, the propagation is relatively stable and reliable with the high safety factor.

\section{Photon-Assisted Millimeter-Wave Generation Scheme}

Millimeter-wave forward transmission has many advantages including strong capacity, simple deployment, and environmental adaptability. In order to achieve high spectral efficiency, it is necessary to support the RoF network system to realize signaling. In fact, in the recent research work, many RoF network systems based on mm-wave band have been proposed and verified experimentally. The following is a brief introduction to several modulation schemes that can generate high-frequency $\mathrm{mm}$-wave based on photonic assistance.

2.1. Directly Modulated Laser (DML). Figure 1 describes the structural principle of the DML scheme. It is a modulation scheme that converts the transmitted information into electrical signals and modulates the optical power, so that the electrical signals can be transmitted on the optical carrier [15]. It mainly superimposes the RF signals on the DC bias of the laser and then modulates them on the light signal through the DML. It generates the electric mm-wave signals after photodiode (PD) detection at the remote end. After filtering out unnecessary noise by the band pass filter (BPF), the generated electric mm-wave signal is amplified by an electrical amplifier (EA) and transmitted to the user through the antenna. Due to it changes the optical intensity information, it is also called intensity modulation (IM) [16, 17]. However, the modulation scheme is only divided into two working states with and without light or little light. At the receiver, it is simply a matter of determining the two states. 


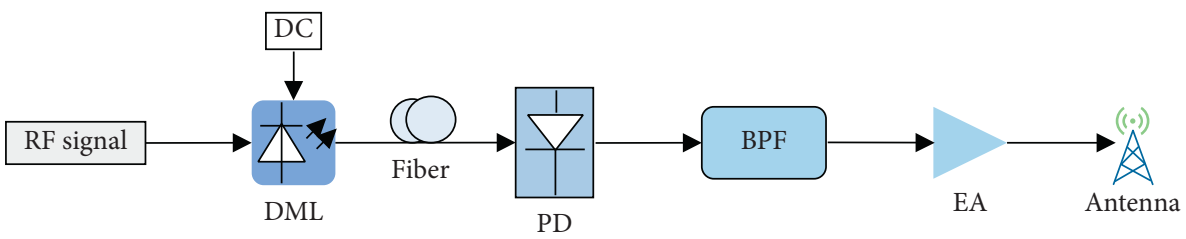

FIGURE 1: DML scheme structure diagram.

The proposed scheme is simple in structure and low in cost. But due to the limited modulation bandwidth of DML, the generated mm-wave frequency is relatively low [18]. Beyond the limit of the baseband signal frequency about $10 \mathrm{GHz}$, the chromatic dispersion (CD) phenomenon will change significantly [19]. Leading to the broadening of the optical pulse, the pulse will overlap with the next pulse which is called intersymbol interference (ISI) [20]. In addition, as the current change would affect the active region refractive index of the semiguided laser and lead to the change of resonant wavelength, additional phase modulation and frequency chirp will be introduced which will affect the modulation performance $[21,22]$. Generally, direct modulation is not suitable for high-frequency RoF network systems. And in most cases, it is used to transmit low-frequency systems. In order to overcome the frequency chirp phenomenon and improve the data transmission rate, people naturally turn their attention to the external modulation scheme [23].

2.2. External Modulation. For frequency higher than $10 \mathrm{GHz}$, the bit error rate (BER) observed by the direct modulation format at the receiver becomes unacceptable. The external modulation associated with the direct modulation could to be selected [23]. It is usually performed by a high-speed external modulator, which generally includes an intensity modulator (IM) [24], a phase modulator (PM) [25], and an electrical absorption modulator (EAM) [26] to produce high quality microwave signals. The principle is shown in Figure 2.

The external modulation scheme uses the connection between the laser source and the external modulator to generate $\mathrm{mm}$-wave. The $\mathrm{RF}$ signal drives the external modulator to produce a light band carrying information. Then, the light band generates mm-wave at the beat frequency in PD [27, 28]. Usually limited by the low RF frequency generated by the RF source and insufficient optical device bandwidth, the external modulation scheme can employ multiple modulators combined with frequency multiplying technology to generate mm-wave signals [29].
Figure 3 shows a schematic of a cascade of multiple external modulators.

The data are modulated by the optical modulator to generate the baseband signal. And then, the second optical modulator is driven by the RF to generate the optical sideband carrying the data [29]. Despite multiple modulator schemes complex structure and higher cost, it can generate higher-frequency stable mm-wave and is no longer limited by the modulation format compared with a single modulator. Unlike the above single external modulation scheme, multiple modulators scheme does not require precoding when generating vector $\mathrm{mm}$-wave signal [30].

2.3. Optical Heterodyne. Besides the DML and external modulation schemes, optical heterodyne modulation is also an efficient method to generate the mm-wave. The heterodyne beat frequency scheme is shown in Figure 4 . The modulated signal enters the PD together with the optical signal emitted by the independent laser. The square-law PD is used to beat the frequency of the two signals [31]. The basic idea of optical heterodyne beat frequency is to generate $\mathrm{mm}$ wave signal whose carrier frequency is the difference of two lasers frequency [32]. The following is the theoretical analysis of the scheme.

It is assumed that the optical signals output by the two lasers can be expressed as

$$
\begin{aligned}
& E_{1}(t)=A_{1} \exp \left[j 2 \pi f_{1} t+j \theta_{1}(t)\right], \\
& E_{2}(t)=A_{2} \exp \left[j 2 \pi f_{2} t+j \theta_{2}(t)\right],
\end{aligned}
$$

where $A_{1}$ and $A_{2}$, respectively, represent the amplitude of two optical signals. $f_{1}$ and $f_{2}$ represent the optical signal frequency. $\theta_{1}(t)$ and $\theta_{2}(t)$, respectively, represent the initial phase information of each laser. After the data information is modulated by laser1, the optical signal can be expressed as

$$
E_{s}(t)=A_{1}[I(t)+j Q(t)] \exp \left[j 2 \pi f_{1} t+j \theta_{1}(t)\right],
$$

where $I(t)+j Q(t)$ represents the modulated baseband vector signal. The two optical signals are then coupled in the OC. The signal is expressed as

$$
E(t)=\frac{A_{1}[I(t)+j Q(t)] \exp \left[j 2 \pi f_{1} t+j \theta_{1}(t)\right]+j A_{2} \exp \left[j 2 \pi f_{2} t+j \theta_{2}(t)\right]}{\sqrt{2}} .
$$




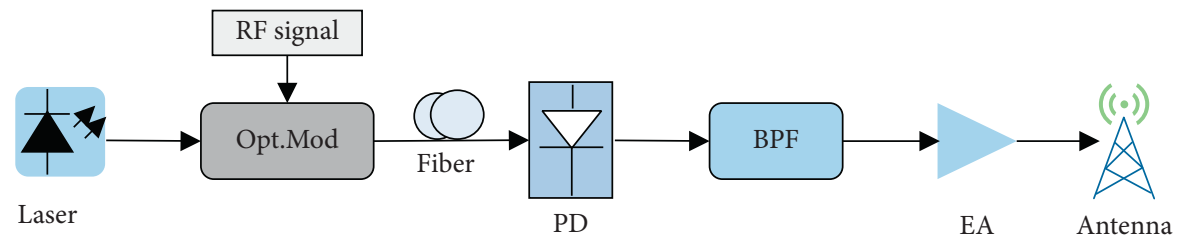

FIGURE 2: External modulation scheme structure diagram. Opt.Mod, optical modulator.

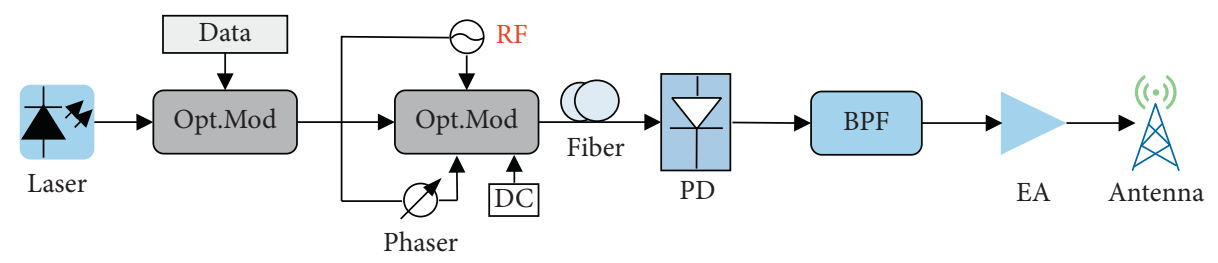

FIGURE 3: Multiple modulators cascade in external modulation scheme structure diagram.

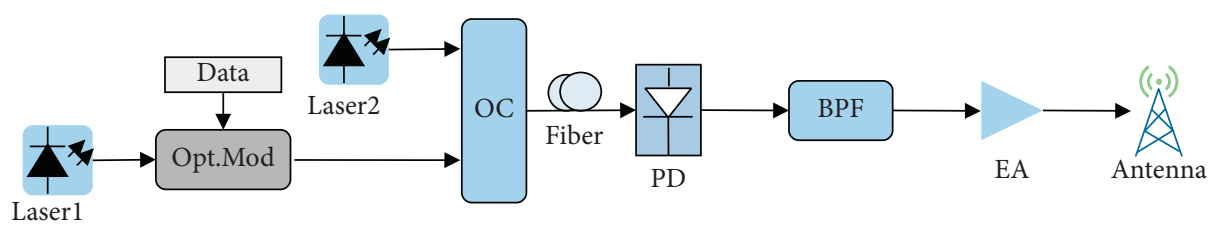

FIgURE 4: Optical heterodyne scheme structure diagram. OC, optical coupler.

After entering PD, the photocurrent generated by the two photo beat can be expressed as [31-33]

$$
\begin{aligned}
I(t)= & R|E(t)|^{2} \\
= & R A_{1}^{2}\left[I^{2}(t)+Q^{2}(t)\right]+R A_{2}^{2} \\
& +2 R A_{1} A_{2} I(t) \sin \left\{2 \pi\left(f_{1}-f_{2}\right) t+\left[\theta_{1}(t)-\theta_{2}(t)\right]\right\} \\
& +2 R A_{1} A_{2} Q(t) \cos \left\{2 \pi\left(f_{1}-f_{2}\right) t+\left[\theta_{1}(t)-\theta_{2}(t)\right]\right\},
\end{aligned}
$$

where $R$ denotes the PD sensitivity, and equation (4) can be simplified as [31-33]

$$
\begin{aligned}
I(t)= & R A_{1}^{2}\left[I^{2}(t)+Q^{2}(t)\right]+R A_{2}^{2} \\
& +2 R A_{1} A_{2}\left\{I(t) \sin \left[2 \pi f_{\triangle} t+\theta_{\triangle}(t)\right]\right. \\
& \left.+Q(t) \cos \left[2 \pi f_{\triangle} t+\theta_{\triangle}(t)\right]\right\},
\end{aligned}
$$

where $f_{\triangle}$ is the difference between $f_{1}$ and $f_{2} \cdot \theta_{\triangle}(t)$ is the difference between $\theta_{1}(t)$ and $\theta_{2}(t)$. It can be seen from equation (5) that the first two terms of the current expression are DC components. The last item is the required mm-wave information. The required frequency can be obtained by controlling the optical frequency difference between the two lasers [32, 34].

The optical heterodyne scheme has the advantages of simple structure, low cost, and flexible generation of millimeter-wave frequency. However, in this scheme, the independent light sources will cause frequency drift and phase noise. The characteristics of the three $\mathrm{mm}$-wave generation schemes are shown in Table 2.

\section{Millimeter-Wave Generation Technology}

3.1. SSB and DSB Vector Signals Generation Based on DML. The principle of SSB or DSB vector mm-wave signal generation based on the DML technology is shown in Figure 5.

It is assumed that the laser traveling wave output of the DML is expressed as

$$
E(t)=A(t) e^{j \omega_{c} t},
$$

where $A(t)$ is the amplitude of the traveling wave, and $A(t)$ is the phase angle. The electric vector RF drive signal generated at the offline end with frequency at $f_{s}$ can be expressed as

$$
V_{m}(t)=V_{m} \cos \left(\omega_{f} t\right)
$$

where $V_{m}$ and $\omega_{f}$, respectively, represent the amplitude and phase angle of the driving signal. The drive signal is then converted into a DAC for the DML. Its output can be expressed as [35]

$$
\begin{aligned}
E(t)= & \frac{\alpha}{2} e^{j \omega_{c} t} \times\left\langle\exp \left\{j\left[\frac{\pi}{V_{\pi}} V_{1} \cos \left(\omega_{f} t\right)\right]\right\}\right. \\
& \left.+\exp \left\{j \frac{\pi}{V_{\pi}}\left[V_{\mathrm{DC}}+V_{2} \cos \left(\omega_{f} t+\theta\right)\right]\right\}\right\rangle \\
= & A(t) \sum_{k=-\infty}^{\infty} \alpha_{k} \exp \left\{j\left[\left(\omega_{c}+k \omega_{m}\right) t+\varphi_{k}\right]\right\},
\end{aligned}
$$


TABLE 2: Comparison of different mm-wave generation schemes [5].

\begin{tabular}{|c|c|c|c|}
\hline Schemes & & Advantages & Disadvantages \\
\hline \multicolumn{2}{|l|}{ DML $[18,22]$} & $\begin{array}{l}\text { (i) Simple structure } \\
\text { (ii) Low cost }\end{array}$ & $\begin{array}{l}\text { (i) Low frequency } \\
\text { (ii) Frequency chirping }\end{array}$ \\
\hline \multirow[t]{2}{*}{ External modulation $[23,27,30]$} & Single modulator & $\begin{array}{l}\text { (i) Simple structure } \\
\text { (ii) Low cost } \\
\text { (iii) MMW good performance }\end{array}$ & $\begin{array}{l}\text { (i) Frequency limitation } \\
\text { (ii) Insertion loss }\end{array}$ \\
\hline & Multiple modulators & $\begin{array}{l}\text { (i) High frequency } \\
\text { (ii) MMW good performance } \\
\text { (i) Simple configuration }\end{array}$ & $\begin{array}{l}\text { (i) Complicated structure } \\
\text { (ii) High insertion loss } \\
\text { (i) Complicated light source }\end{array}$ \\
\hline Optical heterodyne $[31,34]$ & & $\begin{array}{l}\text { (ii) Low cost } \\
\text { (iii) Frequency generation flexibility }\end{array}$ & $\begin{array}{l}\text { (ii) Frequency instability } \\
\text { (iii) Phase noise }\end{array}$ \\
\hline
\end{tabular}

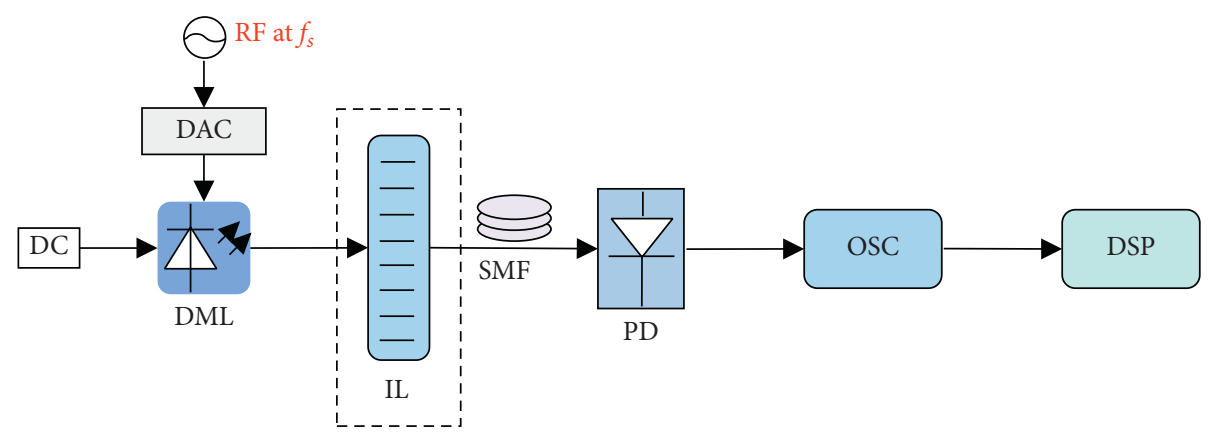

FIGURE 5: Diagram of vector mm-wave signal generation based on SSB or DSB modulation. DAC, digital-to-analog converter; IL, interleaver; SMF, single mode fiber; OSC, oscilloscope.

where $\alpha$ is the DML insertion loss. DSB modulation output can be expressed as [35]

$$
\begin{aligned}
E_{\mathrm{DSB}}(t) \approx & \frac{\alpha}{2} A(t)\left\{\sqrt{1+J_{0}^{2}\left(m_{h}\right)} e^{j\left[\omega_{c} t+\arctan J_{0}\left(m_{h}\right)\right]}\right. \\
& +J_{1}\left(m_{h}\right) e^{j\left[\left(\omega_{c}+\omega_{f}\right) t+(\pi / 2)\right]} \\
& \left.+J_{1}\left(m_{h}\right) e^{j\left[\left(\omega_{c}-\omega_{f}\right) t+(\pi / 2)\right]}\right\},
\end{aligned}
$$

where $m_{h}=\left(\pi V_{h} / V_{\pi}\right)$, and $V_{h}$ and $V_{\pi}$ are the RF drive signal voltage and DML half-wave voltage, respectively. $J$ is the first kind Bessel function [36]. The function image is shown in Figure 6. SSB modulation output can be expressed as [35]

$$
\begin{aligned}
E_{\mathrm{SSB}}(t) \approx & \frac{\alpha}{2} A(t)\left\{\sqrt{2} J_{0}\left(m_{h}\right) e^{j\left(\omega_{c} t+(\pi / 4)\right)}\right. \\
& \left.+2 J_{1}\left(m_{h}\right) e^{j\left[\left(\omega_{c}+\omega_{f}\right) t+(\pi / 2)\right]}\right\} .
\end{aligned}
$$

Here, the modulated signal is transmitted to the remote end via SMF. OSC captures the signal after PD beat frequency. Then, the normal electric vector mm-wave signal can be obtained reasonably by offline DSP. It is worth noting that IL is not required when selecting the DSB modulation format [35].

\subsection{Vector Signals Generation Based on External Modulation.} Vector millimeter-wave signals with carrier suppression can be generated by a dual-arm Mach-Zehnder modulator [30-37], and the schematic diagram is shown in Figure 7.

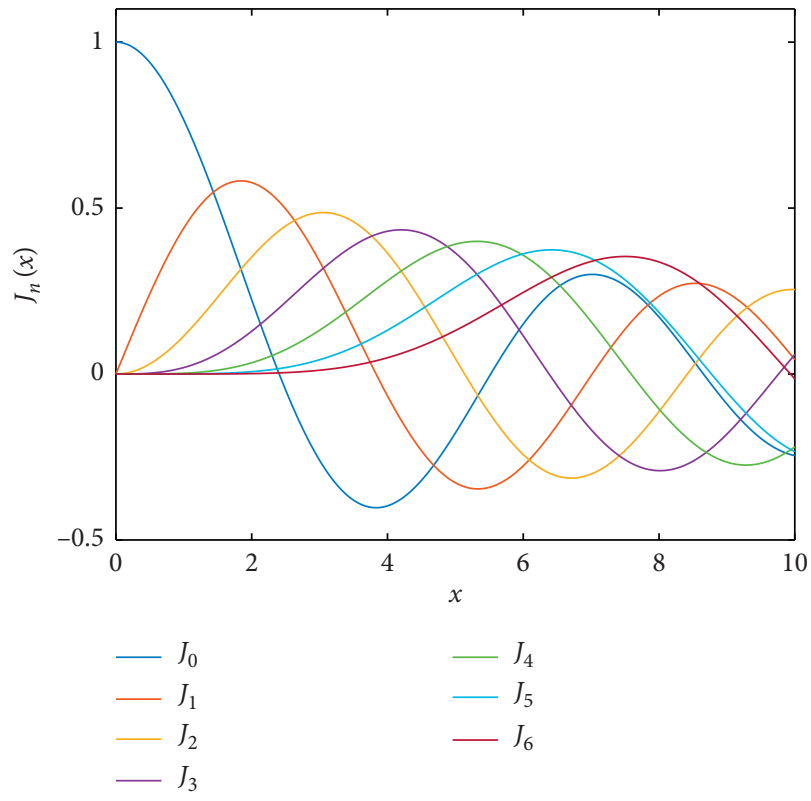

Figure 6: Graph of the first kind Bessel function.

Supposing the output of the laser can be expressed as follows:

$$
E_{\text {in }}=E_{0} \cos \left(\omega_{0} t\right)
$$

where $E_{0}$ and $\omega_{0}$, respectively, represent the amplitude and angular frequency of the optical signal. Both MZM-a and MZM-b are set at the maximum offset point. The electric 


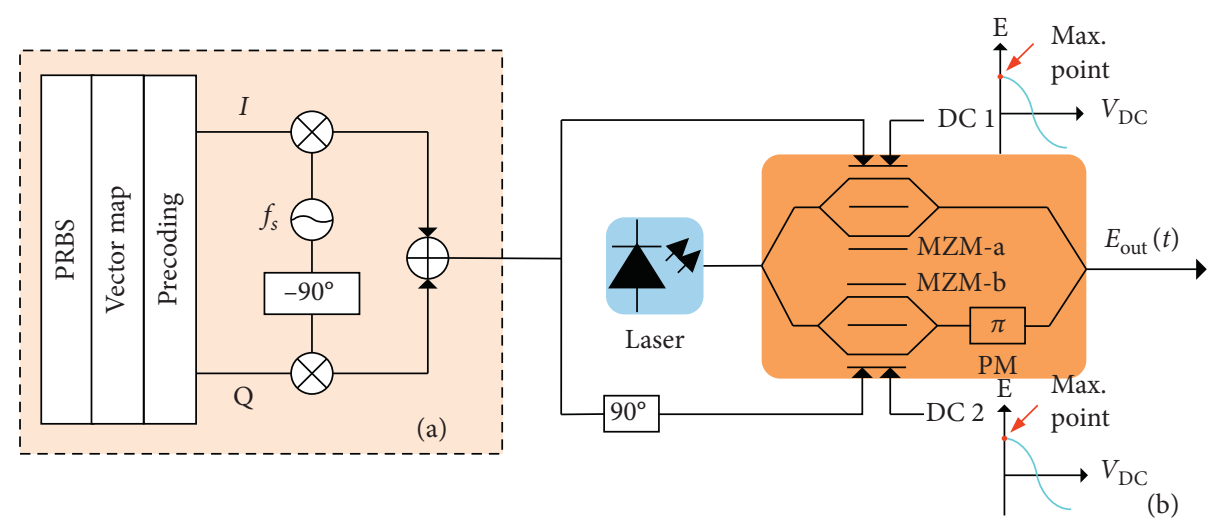

FIGURE 7: Diagram of photonic vector mm-wave signal generation. (a) Block diagram of offline vector signal generation; PRBS, pseudo random binary sequence. (b) Principle of mm-wave generation of vector signal [30].

vector signals incident on MZM-a and MZM-b are $V_{a}=$ $V_{m} \cos \left[\omega_{\mathrm{RF}} t+\theta(t)\right]$ and $V_{b}=V_{m} \cos \left[\omega_{\mathrm{RF}} t+\theta(t)+(\pi / 2)\right]$, respectively. $V_{m}$ represents the amplitude of electric vector signal, and $\theta(t)$ represents the phase. $\omega_{R F}$ represents the central frequency of the RF drive signal. After the output of MZM-b is deflected by $180^{\circ}$ phase, the optical signal generated together with MZM-a can be expressed as [30]

$$
\begin{aligned}
E_{\text {out }}= & -E_{0} \sum_{n=1}^{\infty} J_{4 n-2}[m(t)]\left(\cos \left\{\left[\omega_{0}-(4 n-2) \omega_{R F}\right] t-2 \theta(t)\right\}\right. \\
& \left.+\cos \left[\left[\omega_{0}+(4 n-2) \omega_{\mathrm{RF}}\right] t+2 \theta(t)\right]\right),
\end{aligned}
$$

where $m(t)$ stands for the modulation index. Within the effective range, ignoring higher-order optical sideband greater than $J_{2}$, equation (12) can be simplified as [30]

$$
\begin{aligned}
E_{\text {out }}= & -E_{0} J_{2}[m(t)]\left\{\cos \left[\left(\omega_{0}+2 \omega_{\mathrm{RF}}\right) t+2 \theta(t)\right]\right. \\
& \left.+J_{2}[m(t)] \cos \left[\left(\omega_{0}-2 \omega_{\mathrm{RF}}\right) t-2 \theta(t)\right]\right\} .
\end{aligned}
$$

The signal generated after PD beat frequency can be expressed as [30]

$$
i_{4 \omega_{\mathrm{RF}} t}=\frac{1}{2} R J_{2}^{2}[m(t)] \cos \left[4 \omega_{\mathrm{RF}} t+4 \theta(t)\right] .
$$

You can see that the vector signal produced is four times as frequent as the original signal $[38,39]$. That is to say, we can get a vector mm-wave signal of quadruple frequency. Therefore, the vector signal needs to be precoded before modulation. Generally speaking, only phase precoding is required for quadrature phase shift keying (QPSK) signals. For multiple quadrature amplitude modulation (M-QAM) signals, amplitude and phase precoding are both required.

3.3. Multifrequency Vector Signals Generation Based on MZM. Here, we briefly introduce the experiment of generating $\mathrm{mm}$ wave with multiple frequency and appropriate amount by selecting sideband signal through wavelength selective switch (WSS) [40]. Its schematic diagram is shown in Figure 8.

MZM works in the carrier suppression mode. The modulated optical signals are suppressed by a carrier wave or by a pair of waves. The unsubdued sideband signals carry vector signals. Then, the symmetric n-order sideband retained by WSS can be selected to generate signals of $2 \mathrm{n}$ times RF frequency via PD beat frequency [38, 39].

Besides this, it also can generate a photon quadrate vector mm-wave based on a single MZM without WSS. Offsetting MZM to the maximum transmission point, then offline precoding RF signals are used to drive MZM. Properly modulating the drive voltage produces two second-order photon carriers. Other subcarriers are suppressed [38, 41]. In this way, after PD beat frequency, quadruple frequency vector $\mathrm{mm}$-wave signal can be generated. Assume that the output signal of MZM can be expressed as [38, 41, 42]

$$
E_{\mathrm{MZM}}(t)=2 K_{1} \sum_{n=-\infty}^{\infty} J_{2 n}(k) \exp \left[j 2 \pi\left(f_{c}+2 n f_{s}\right) t+j 2 n \varphi(t)\right] \text {, }
$$

where $K_{1}$ is a constant. $J_{2 n}(k)$ is the $2 n$ order Bessel function. The function image is shown in Figure 9. $k$ is the modulation index.

As we can see from the figure, when $k$ increases from 0 to $3, J_{0}$ numeration continues to decrease and $J_{2}, J_{4}$, and $J_{6}$ continue to increase. When $k$ is set to $2.4048, J_{0}$ goes to 0 . In other words, the MZM-modulated voltage is set to the maximum point. At the same time, the center carrier is suppressed. Other subcarriers of order greater than 2th order can be ignored. Therefore, the output of MZM is mainly two second-order subcarriers. Equation (15) can be simplified as [41]

$$
\begin{aligned}
E_{\mathrm{MZM}}(t) \approx & 2 K_{1} J_{2}(k)\left\{\exp \left[j 2 \pi\left(f_{c}+2 f_{s}\right) t+j 2 \varphi(t)\right]\right. \\
& \left.+\exp \left[j 2 \pi\left(f_{c}-2 f_{s}\right) t-j 2 \varphi(t)\right]\right\} .
\end{aligned}
$$

After the remote PD beat, the RF signal can be expressed as follows:

$$
i_{\mathrm{RF}}(t)=\frac{1}{2} R J_{2}^{2}(k) \cos \left[2 \pi \cdot 4 f_{s} t+4 \varphi(t)\right] .
$$

It can be obtained from equation (17) that the frequency of the RF signal is 4 times that of the drive signal. However, 


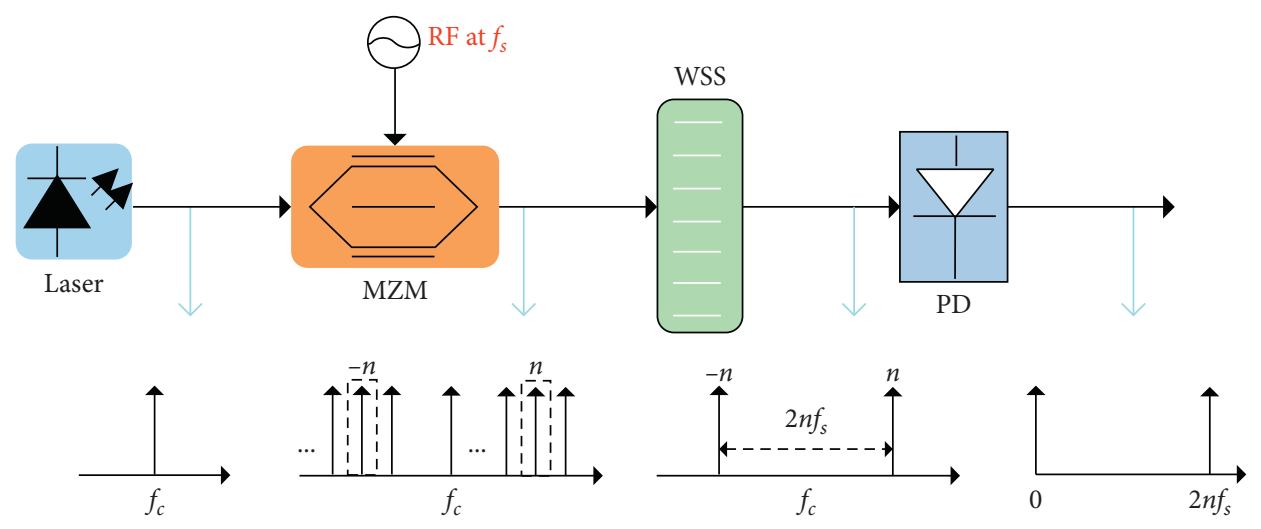

FIgURE 8: Multifrequency vector millimeter-wave generation schematic.

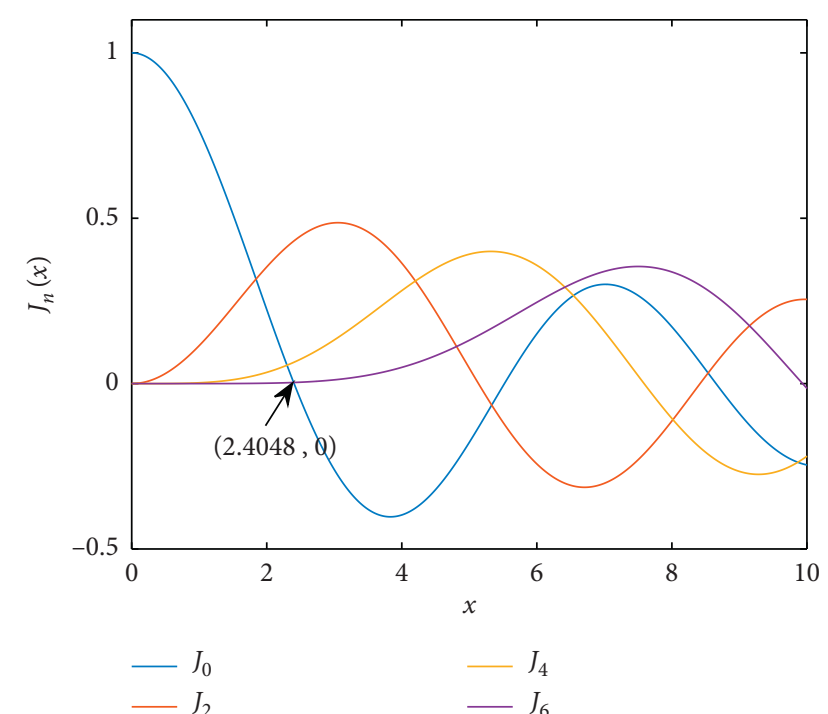

Figure 9: The Bessel function graph of order $2 n$.

the phase will change after the detection of square-law PD. Das et al. [42] describe that normal vector signals can be obtained by precoding technique.

\subsection{Generation of Multifrequency Vector Millimeter-Wave} Based on a Phase Modulator. Compared with the abovementioned intensity modulator or MZM, the PM has a smaller insertion loss. This results in a higher optical signalto-noise ratio (OSNR) for the optical signal it produces. And its stability is better because there is no DC bias. Figure 10 shows the schematic diagram of generating a photon multifrequency vector mm-wave signal based on a PM and precoding [43].

Here, we take the example of quadruple frequency and briefly introduce the principle of its generation. The offline precoding vector signals with frequency at $f_{s}$ are generated including PRBS, vector mapping, precoding, low-pass filter, and digital upconversion. The signal output by the PM modulator can be represented as follows $[43,44]$ :

$$
\begin{aligned}
E_{\mathrm{PM}}(t)= & K_{1} \exp \left[j 2 \pi f_{c} t+j \varphi(t)+j \pi V_{\mathrm{RF}}(t) / V_{\pi}\right] \\
= & K_{1} \sum_{n=-\infty}^{\infty} j^{n} J_{n}(k) \exp \left[j 2 \pi\left(f_{c}+n f_{s}\right) t\right. \\
& +j n \theta(t)+j \varphi(t)],
\end{aligned}
$$

where $K_{1}$ represents the amplitude of the CW light wave. $\varphi(t)$ stands for the random phase noise. $J_{n}$ is the first Bessel function of $n$ order. $k$ is the modulation index of the phase modulator. The output carrier signal can be seen from Figure 10 as multiple photon carriers with frequency interval of $f_{c}$. WSS is then used to select two second-order photonic carriers with frequency intervals of $4 f_{s}$ from the output of the phase modulator. Its output can be written as $[25,43,45]$

$$
\begin{aligned}
E_{\mathrm{WSS}}(t)= & -K_{1} J_{2}(k)\left\{\operatorname { e x p } \left[j 2 \pi\left(f_{c}+2 f_{s}\right) t+j 2 \theta(t)\right.\right. \\
& \left.+j \varphi(t)]+\exp \left[j 2 \pi\left(f_{c}-2 f_{s}\right) t-j 2 \theta(t)+j \varphi(t)\right]\right\} .
\end{aligned}
$$

The signal selected by WSS generates a $4 f_{s}$ vector mmwave signal with a frequency of $4 f_{s}$ via $\mathrm{PD}$ beat. Its current value can be expressed as (except the DC component)

$$
i_{\mathrm{RD}}(t)=\frac{1}{2} R J_{2}^{2}(k) \cos \left[2 \pi \cdot 4 f_{s} t+4 \theta(t)\right] .
$$

The random phase noise is eliminated because the two second-order photon carriers from the same laser source are phase locked with frequency locking. However, the dispersion effect of optical fiber reduces the consistency of the two second-order photon carriers. Therefore, random phase noise cannot be eliminated. The performance of the generated mm-wave is reduced. Furthermore, in order to ensure that the generated vector millimeter-wave signal with a frequency of $4 f_{s}$ can obtain the standard modulation format, the parameters should be adjusted to make the amplitude term $J_{2}^{2}(n)$ and phase term $\theta(t)$ meet the standard vector modulation rules $[43,45,46]$.

Based on the combined action of the phase modulator and WSS, this technique can theoretically generate vector $\mathrm{mm}$-wave signals with arbitrary photonic multifrequency. $\mathrm{Li}$ et al. [43] have successfully generated 3 times optical vector $\mathrm{mm}$-wave signal based on this technique. Using WSS to 


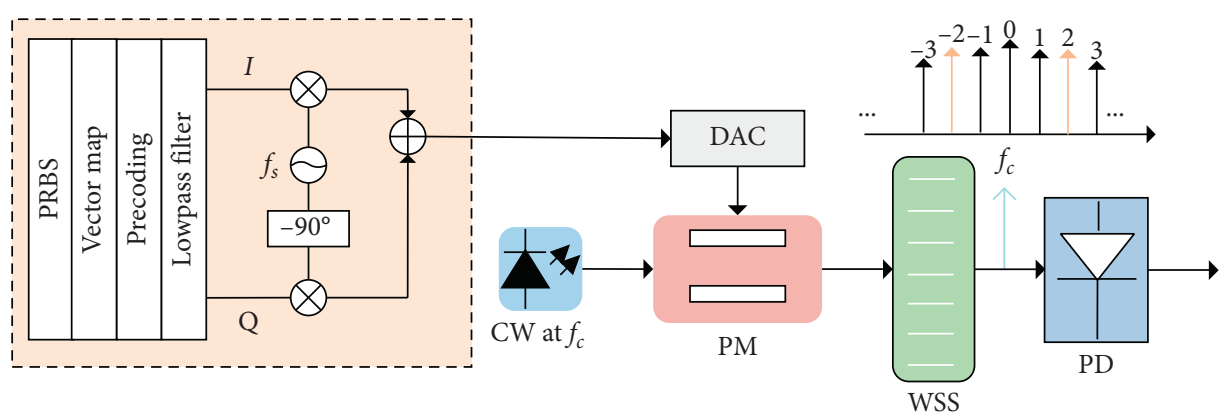

Figure 10: The principle diagram of multifrequency vector signal generation.

select the carrier output by the phase modulator, two subcarriers have several different asymmetric combinations such as $(-3,0),(-2,1),(-1,2)$, and $(0,3)$. It also successfully generates 5 times frequency vector $\mathrm{mm}$-wave signal. WSS selects order -1 and order +4 photon carriers [43, 47]. Ma et al. have already successfully verified that the phase modulator generated septupling and nonuple frequency vector mm-wave signals, respectively $[48,49]$.

\section{Large Capacity Transmission System Structure}

In the previous section, we introduced the modulation format of high-frequency mm-wave generated over optical fiber links in the RoF network system. Based on the photonic $\mathrm{mm}$-wave technology, we can reduce the bandwidth required by the system devices by lessening the signal baud rate to further improve the data transmission capacity of the RoF network system. The following would introduce several methods and structures to achieve large capacity transmission based on RoF network systems.

4.1. Optical PDM Combined with MIMO. The polarization of light is the manifestation of the s-wave characteristic of light and has a very good transmission characteristic in the optical communication system. Polarization multiplexing technology can double the transmission capacity of the system [50]. At present, the optical polarization division multiplexing (PDM) technology has been very mature. Due to the maturity of optical PDM technology, many researchers are trying to combine it with the Multiple-Input MultipleOutput (MIMO) technology to realize superlarge capacity data transmission [51]. The following will be combined with its block diagram to briefly introduce the principles of each part. Its block diagram is shown in Figure 11.

It mainly consists of four parts: optical baseband transmitter, optical heterodyne upconverter, radio signal transceiver antennas, and wireless $\mathrm{mm}$-wave signal receiver. The main function of the transmitter is to generate optical modulation PDM signals. Then, the signal is generated by a polarization multiplexer. The signal transmitted to the polarization division multiplexer is sent by the modulator. Here, the modulator is driven by electronic data from the transmitter [53]. The principle of polarization multiplexers is described later. Then, the optical PDM signal is transmitted to the optical heterodyne upconverter by an optical fiber. The main work of this part is to convert the baseband signal sent by the transmitter into mm-wave frequency band signal. In the Figure 11, the optical frequency difference between the frequency of LO and the baseband signal is the central frequency of mm-wave. Then, polarizing beam splitter (PBS) and OC are used to obtain polarized coherent millimeter-wave signals in $X$ and $Y$ directions after upconversion by PD [54]. In the wireless connection part, there are two antennas on each side to form a $2 \times 2$ MIMO wireless link. At the receiver, the signals need to be converted into baseband signal through downconversion and finally sent to the digital signal processing part, where the signal is optimized to reduce BER and improve the transmission performance of the system.

The detailed principle of the optical transmitter part and the basic characteristics of MIMO transmission are described below. At the transmitter, the laser generates a continuous wave $(\mathrm{CW})$, which is then modulated through the $I / Q$ modulator. And the arbitrary waveform generator (AWG) generates the desired modulation signal, which is amplified by the EA to drive the I/Q modulator [55]. Optical PDM technique is realized by the multiplexer. A polarization division multiplexer includes an OC for dividing the signal into two branches, a delay line (DL) for providing symbol delay, and an attenuator (ATT) for balancing the power of the two branches $[54,55]$. The two branch signals are recombined into a branch signal via PBS and transmitted to a distant base station via SMF. Figure 12 is the schematic diagram of the optical baseband transmitter part.

Besides, we introduced the principle of the MIMO connection part too, and it can be briefly described as follows [55]:

$$
\left(\begin{array}{c}
r_{x} \\
r_{y}
\end{array}\right)=\left(\begin{array}{cc}
H_{x x} & H_{y x} \\
H_{x y} & H_{y y}
\end{array}\right) \cdot\left(\begin{array}{c}
s_{x} \\
s_{y}
\end{array}\right)+\left(\begin{array}{c}
n_{x} \\
n_{y}
\end{array}\right),
$$

where $\left(r_{x} r_{y}\right)^{T}$ is a wireless transmission to receive a signal; $\left(\begin{array}{ll}s_{x} & s_{y}\end{array}\right)^{T}$ and $\left(n_{x} n_{y}\right)^{T}$ denote the transmitted signal and the noise. The first term on the right of the equal sign can be described as [55] 


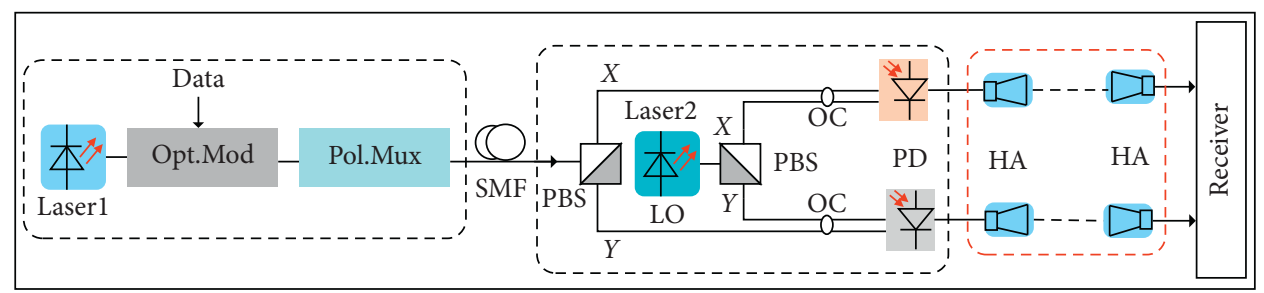

FIgURE 11: Structure diagram of optical PDM combined with MIMO. Pol.Mux, polarization multiplexer; LO, local oscillator; HA, horn antenna [52].

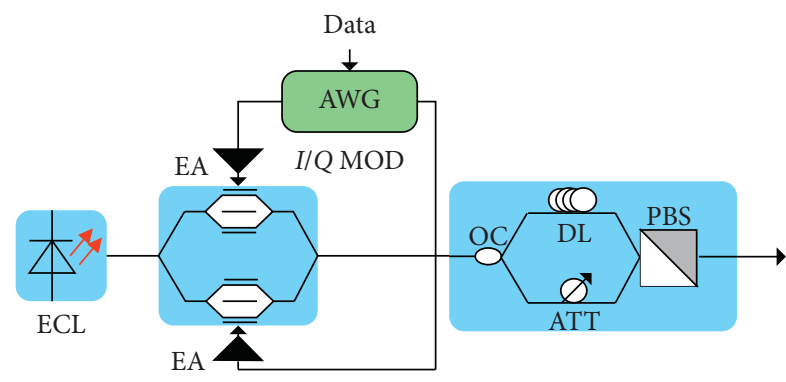

FIGURE 12: Schematic diagram of the optical baseband transmitter.

$$
\begin{aligned}
\left(\begin{array}{cc}
H_{x x} & H_{y x} \\
H_{x y} & H_{y y}
\end{array}\right)= & H_{\text {fiber }} \cdot H_{\text {wireless }}=\left(\begin{array}{ll}
m_{x x} & m_{y x} \\
m_{x y} & m_{y y}
\end{array}\right) \\
& +\left(\begin{array}{ll}
h_{x x} & h_{y x} \\
h_{x y} & h_{y y}
\end{array}\right),
\end{aligned}
$$

where the two items on the right side of the equation are the Jones transmission elements of fiber optics and wireless links. In [56], the ROF network transmission of $5 \mathrm{~Gb} / \mathrm{s}$ based on PDM and MIMO has been successfully verified. In [57], it is confirmed that $224 \mathrm{~Gb} / \mathrm{s}$ information data can be transmitted.

4.2. Advanced Multilevel Modulation. The optical fiber wireless network system based on the combination of optical PDM and MIMO reception can realize the transmission of ultralarge capacity data, but its upper limit is far larger than that. It is well known that high-order I/Q modulation (such as $\mathrm{M}-\mathrm{QAM}$ ) is used to improve spectrum efficiency $[58,59]$. Therefore, in the signal transmitter part, when the advanced multilevel modulation signal is modulated on the I/Q modulator, the transmission capacity of the ROF network system based on the combination of optical PDM and MIMO can be increased several times. Due to the principle is similar to that in the previous section, we would not elaborate further here.

In addition, it is necessary to introduce the DSP part of the receiver. Compared with the ADC and the basic DSP algorithm in the previous section $[56,59,60]$, the DSP algorithm of this structure is partly complex. Its sequence block diagram is shown in Figure 13.

After the signal is converted by ADC, the two signals (polarization states of $X$ and $Y$ ) are restored by the same DSP algorithm. The converted signal is converted into baseband

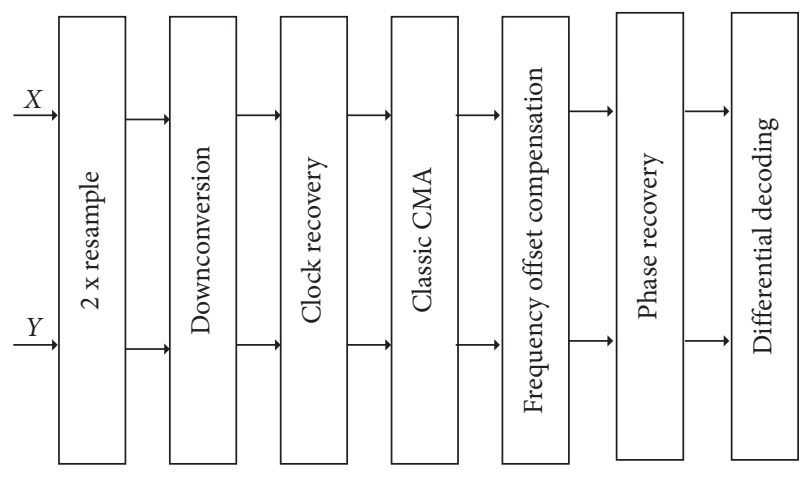

FIgURE 13: DSP algorithm flowchart at receiver.

signal by double resampling and downconversion immediately [60]. Then, a series of classical algorithms are used to restore the signal. These include clock recovery, classical constant modulus algorithm (CMA), and frequency offset compensation and phase recovery. After a series of corrections, BER comparisons are made through differential decoding [61, 62].

4.3. Optical Multicarrier Modulation. All the above are effective methods based on optical single carrier modulation, while optical multicarrier modulation can effectively reduce the transmission baud rate under the same conditions. It can also realize ultralarge capacity data transmission [63]. Figure 14 shows the schematic diagram of the combination of multicarrier modulation and the RoF transmission network system.

As shown in Figure 14, the system is similar to dense wavelength division multiplexing (DWDM), and its principle is explained by three optical carrier channels (ch1, 2, and 3) combined with optical carrier suppression (OSC) technology [64]. Here, the three-carrier signal sent by the transmitter is divided into two channels after passing through the BPS. Laser2 provides LO frequency to beat frequency or heterodyne to produce $\mathrm{mm}$-wave signals [63-65]. The following describes the generation of threecarrier signal principle. Schematic diagram of the optical baseband transmitter is shown in Figure 15.

After passing through the $I / Q$ modulator, the electrical signal is split in two by an OC. One route produces the desired signal (ch2) via a polarization multiplexer and the other is modulated by MZM. Then, it is driven by RF signal and offset at zero to achieve optical carrier suppression. 


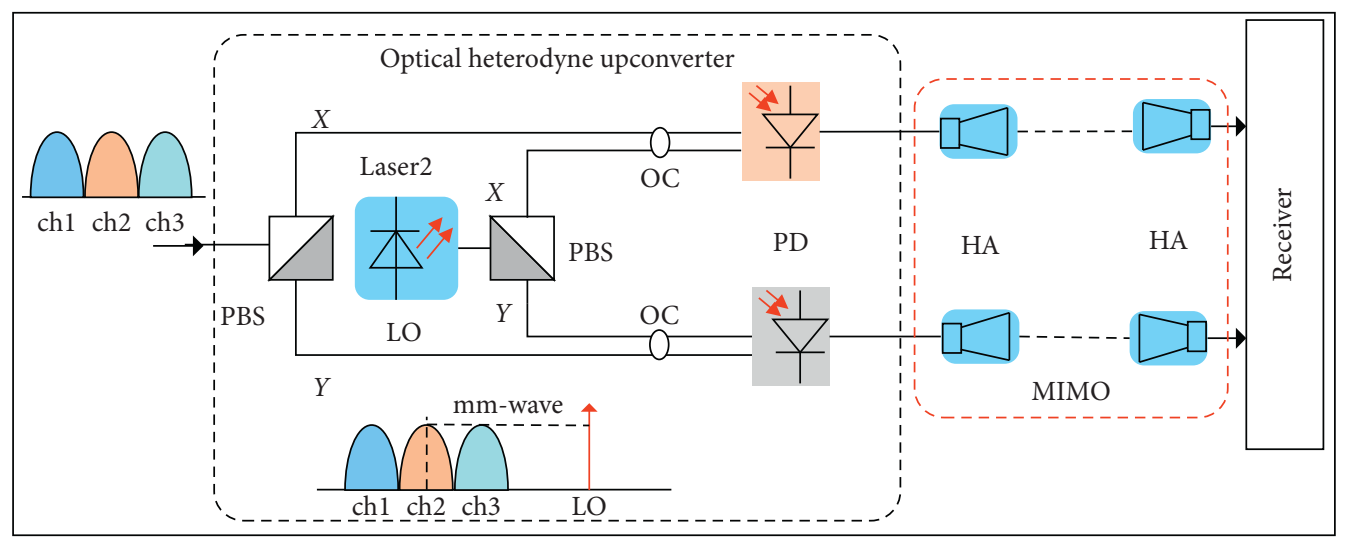

FIgURE 14: Schematic diagram of the combination of multicarrier modulation and the optical fiber wireless transmission network.

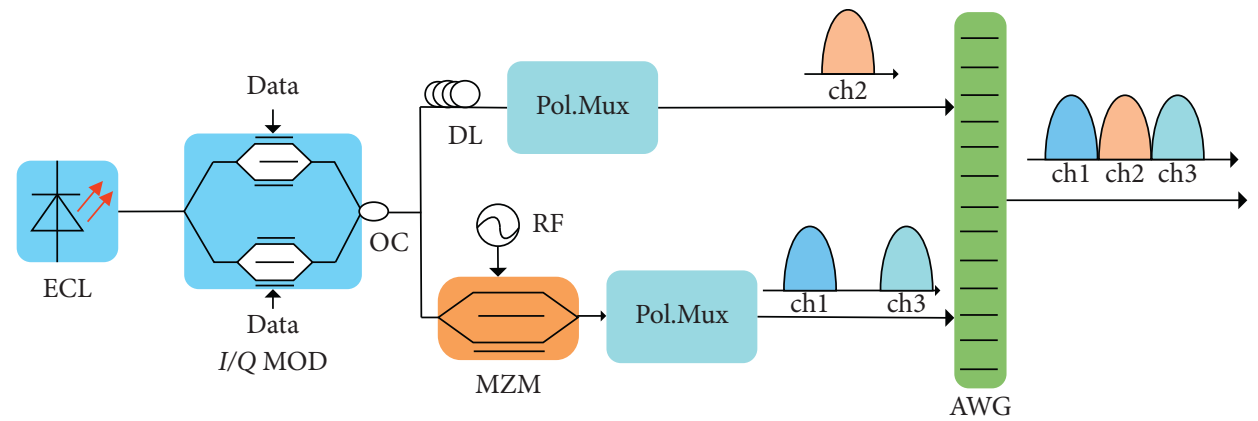

FiguRE 15: Schematic diagram of optical multicarrier signal generation.

After the suppression of the signal, through polarization multiplexer, ch1 and ch3 signal finally through AWG and then transmitted by SMF $[65,66]$. It is worth noting that the subsequent DSP parts of the optical multicarrier modulation technology system are similar to those described in the first two sections, with the only difference being that the front end requires channel demultiplexing. The structure diagram is shown in Figure 16.

4.4. Antenna Polarization Multiplexing. Various modulation schemes over optical fiber links are already capable of transmitting huge amounts of data, but scientists and operators will not be satisfied. In general, the antennas commonly used in our field will show large or small polarization (commonly understood as the direction of the electric field), and the antenna can improve the information transmission efficiency through gain [67]. Therefore, we can further improve the transmission capacity from the angle of antenna polarization. Figure 17 shows a schematic diagram of the antenna polarization multiplexing system.

There are two polarization states of antenna, namely, $E$ polarization and $H$ polarization, which most people like to call horizontal polarization (H-pol) and vertical polarization (V-pol). The MIMO wireless link in the figure consists of four transmitting antennas and four receiving antennas. It can be divided into two parts, one of which is set as horizontal polarization to form an $\mathrm{H}$-polarized $\mathrm{HA}$

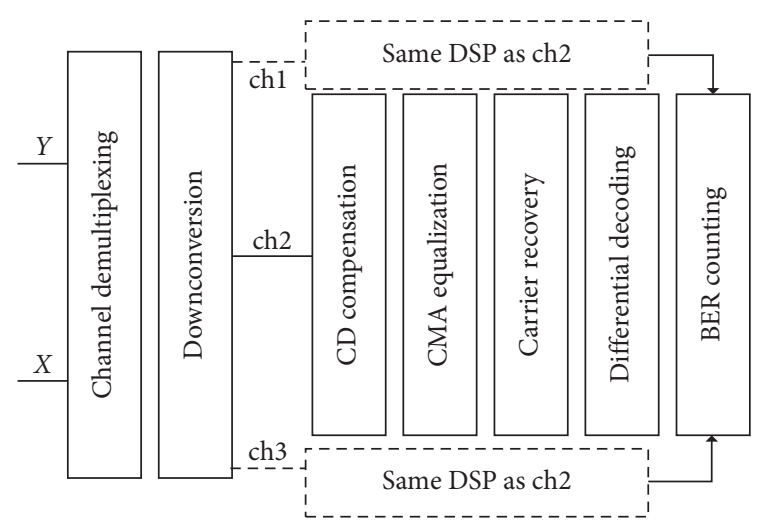

FIGURE 16: Optical multicarrier modulation DSP algorithm part of the structure.

array to transmit ch1, and the other to form a V-polarized HA array to transmit ch2 [68]. It is worth noting that the signals received by the receiving antenna have to be sent into the OSC and then restored and optimized by a series of DSP part after ADC. Figure 18 shows the schematic diagram.

The signal generation part is still similar to the principle shown above. Here, an additional WSS equivalent to a BPS is added to select the signal spectrum bandwidth. After being selected by WSS, the signal is provided by LO to beat frequency and generate modulated signals $[52,67,68]$. 


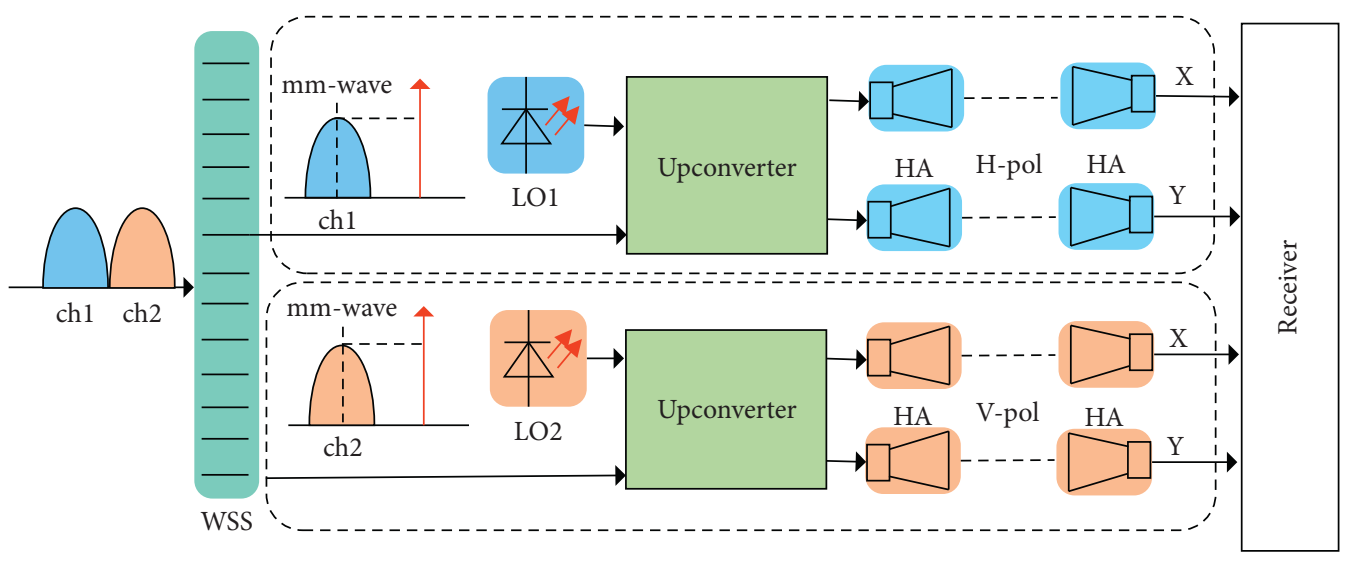

FIgURE 17: Antenna polarization multiplexing system structure diagram.

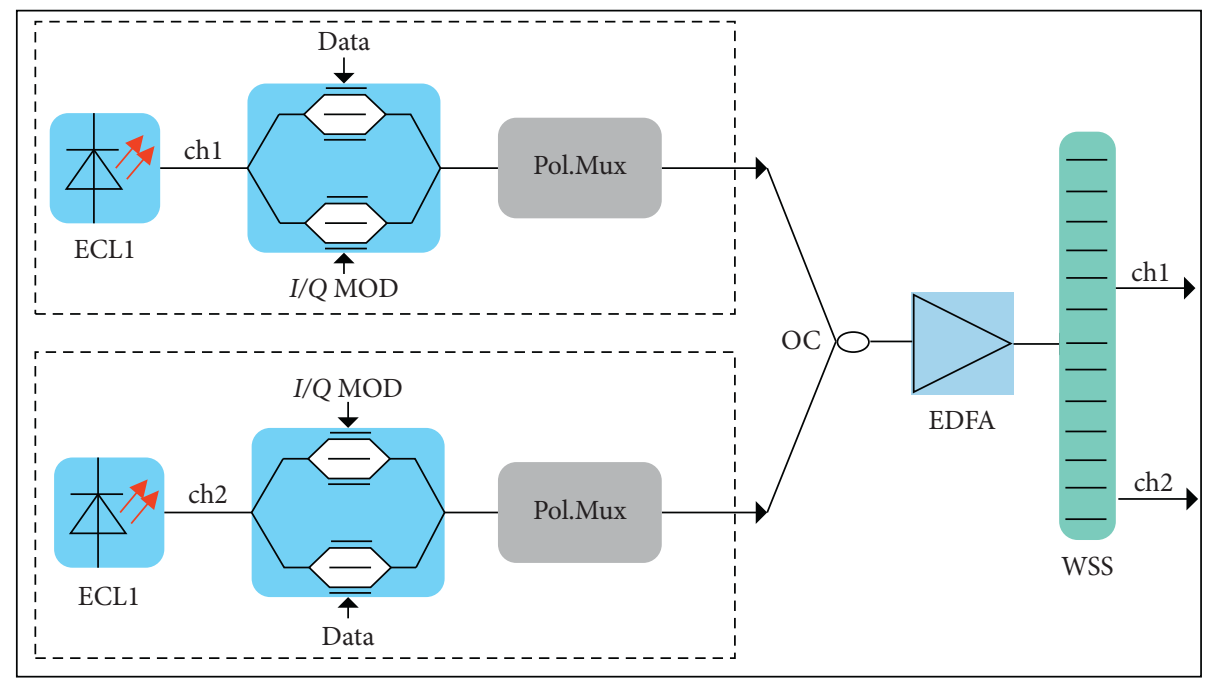

FIGURE 18: Schematic diagram of antenna polarization multiplexing.

\section{Conclusion}

At the beginning of this paper, people's demand for high broadband and high capacity communication is introduced, and then, the central topic of the fiber optic radio network is introduced. This paper introduces the structure of the RoF network system and the advantages of high-frequency $\mathrm{mm}$ wave signal transmission. After that, several modulation formats that generate mm-wave frequency band on RoF based on photon assisted are introduced. Based on these modulation schemes, several vector multifrequency $\mathrm{mm}$ wave signal generation techniques are reviewed. Finally, based on the modulation formats mentioned above, several advanced highly complex methods and structures to realize data transmission with very large capacity are listed. To sum up, the RoF network system will continue to be a research hotspot for experts in the field of communication in the next decade. Due to its high broadband and ultrahigh-speed transmission characteristics and its high flexibility in access, its applications are very extensive. However, with the increase of distance and the constant demand of communication capacity, the transmission network system still has more or less shortcomings, and there are still many undiscovered realms to be explored.

\section{Data Availability}

No data were used to support this study.

\section{Conflicts of Interest}

The authors declare that they have no conflicts of interest.

\section{Acknowledgments}

This work was supported by funding from National Key Research and Development Program of China Stem Cell and Translational Research (2018YFB1801500), National Natural Science Foundation of China (61675048), and Research Project of Key Laboratory for Information Science of Electromagnetic Waves MOE (EMW201911). 


\section{References}

[1] A. Stöhr, A. Akrout, R. Buß et al., "60 GHz radio-over-fiber technologies for broadband wireless services," Journal of Optical Networking, vol. 8, no. 5, pp. 471-487, 2009.

[2] A. N. Uwaechia and M. Nor Muzlifah, "A comprehensive survey on millimeter wave communications for fifth-generation wireless networks: feasibility and challenges," Access IEEE, vol. 6, pp. 62367-62414, 2020.

[3] C. Lim, Y. Tian, C. Ranaweera, T. A. Nirmalathas, E. Wong, and K.-L. Lee, "Evolution of radio-over-fiber technology," Journal of Lightwave Technology, vol. 37, no. 6, pp. 1647-1656, 2019.

[4] T. R. Raddo, S. Rommel, B. Cimoli, and I. T. Monroy, "The optical fiber and mmWave wireless convergence for $5 \mathrm{G}$ fronthaul networks," in Proceedings of the 2019 IEEE 2nd 5G World Forum (5GWF), pp. 607-612, IEEE, Dresden, Germany, September 2019.

[5] N. Mohamed, S. M. Idrus, and A. B. Mohammad, "Review on system architectures for the millimeter-wave generation techniques for RoF communication link," in Proceedings of the 2008 IEEE International RF and Microwave Conference, pp. 326-330, IEEE, Kuala Lumpur, Malaysia, December 2008.

[6] S. Islam, M. F. Khan, M. Z. Hossan, and M. A. Amin, "An overview of radio over fiber (RoF) technology," in Proceedings of the 2019 2nd International Conference on Intelligent Computing, Instrumentation and Control Technologies (ICICICT), pp. 749-752, IEEE, Kannur, India, July 2019.

[7] M. H. Sanan, K. A. Alam, M. Z. Rafique, and B. Khan, "Quality of service enhancement in wireless LAN: a systematic literature review," in Proceedings of the 2019 13th International Conference on Mathematics, pp. 1-8, Actuarial Science, Computer Science and Statistics (MACS), Karachi, Pakistan, December 2019.

[8] H. Ji, C. Sun, and W. Shieh, "On the bandwidth efficiency of analog and digital RoF for mobile fronthaul transmission link," in Proceedings of the 45th European Conference on Optical Communication (ECOC 2019), pp. 1-3, IEEE, Dublin, Ireland, September 2019.

[9] S. Mahajan, S. Lodh, and A. K. Pandit, "Generation of MMwave in radio-over-fiber photonic transmission system," in Proceedings of the 2019 International Conference on Advances in Computing, Communication and Control (ICAC3), pp. 1-5, IEEE, Mumbai, India, January 2019.

[10] W. Haiming, H. Wei, C. Jixin, S. Bo, and P. Xiaoming, "IEEE 802.11aj (45GHz): a new very high throughput millimeterwave WLAN system," China Communications, vol. 11, no. 6, pp. 51-62, 2014.

[11] J. Chen, W. Lin, P. Yan, J. Xu, D. Hou, and W. Hong, "Design of mm-wave transmitter and receiver for 5G," in Proceedings of the 2017 10th Global Symposium on Millimeter-Waves, pp. 92-93, IEEE, Hong Kong, China, May 2017.

[12] F. Khan and J. Pi, "Millimeter-wave mobile broadband: unleashing 3-300 GHz spectrum," in Proceedings of the IEEE Wireless Communications Network Sarnoff Symposium, IEEE, Princeton, NJ, USA, May 2011.

[13] Z. Hao, "Planar wideband mm-wave antennas for mm-wave 5G applications," in Proceedings of the 2019 International Conference on Microwave and Millimeter Wave Technology (ICMMT), pp. 1-3, IEEE, Guangzhou, China, May 2019.

[14] X. Li, J. Yu, L. Zhao, K. Wang, W. Zhou, and J. Xiao, "1-Tb/s photonics-aided vector millimeter-wave signal wireless delivery at D-band," in Proceedings of the 2018 Optical Fiber Communications Conference and Exposition (OFC), pp. 1-3, IEEE, San Diego, CA, USA, March 2018.
[15] L. Zhao and J. Yu, "10 Gb/s 16-quadrature amplitude modulation signal delivery over a wireless fiber system by using a directly modulated laser for electrical/optical conversion," Chinese Optics Letters, vol. 1360601 pages, 2015.

[16] N. H. Zhu, Z. Shi, Z. K. Zhang et al., "Directly modulated semiconductor lasers," IEEE Journal of Selected Topics in Quantum Electronics, vol. 24, no. 1, pp. 1-19, 2018.

[17] M. Alhalabi, F. I. El-Nahal, and N. Taşpinar, "Comparison of different modulation techniques for optical OFDM intensity modulation and direct detection IM/DD system," in Proceedings of the 2019 IEEE 7th Palestinian International Conference on Electrical and Computer Engineering (PICECE), pp. 1-4, IEEE, Gaza, Palestine, March 2019.

[18] C. R. S. Fludger, J. E. A. Whiteaway, and P. J. Anslow, "Electronic equalisation for low cost $10 \mathrm{Gbit} / \mathrm{s}$ directly modulated systems," in Proceedings of the Optical Fiber Communication Conference, IEEE, Los Angeles, CA, USA, February 2004.

[19] A. S. Karar, M. Yañez, Y. Jiang, J. C. Cartledge, J. Harley, and K. Roberts, "Electronic dispersion pre-compensation for 10709-Gb/s using a look-up table and a directly modulated laser,” Optics Express, vol. 19, pp. B81-B89, 2011.

[20] A. L. Balan and N. D. Alexandru, "Inter-symbol interference free pulses for transmission over intensity-modulated channels," in Proceedings of the 2014 10th International Conference on Communications (COMM), pp. 1-4, IEEE, Bucharest, Romania, May 2014.

[21] A. Gharba, "Optical transmission performance for DML considering laser chirp and fiber dispersion using AMOOFDM," in Proceedings of the International Congress on Ultra Modern Telecommunications and Control Systems, pp. 1022-1026, IEEE, Moscow, Russia, October 2010.

[22] V. Rivera-Silva, A. J. Millán-Mejía, and R. GutiérrezCastrejón, "Automatic classification of the frequency chirp in directly modulated lasers using cross-correlation," in Proceedings of the 2012 9th International Conference on Electrical Engineering, pp. 1-6, Computing Science and Automatic Control (CCE), Mexico City, Mexico, September 2012.

[23] T. Cseh, T. Berceli, E. Udvary, and G. Fekete, "Optical transmission of OFDM m-QAM RF signals: comparison of direct and external modulations," in Proceedings of the 2012 14th International Conference on Transparent Optical Networks (ICTON), pp. 1-5, IEEE, Coventry, UK, July 2012.

[24] S. A. Khwandah, J. P. Cosmas, I. A. Glover, P. I. Lazaridis, N. R. Prasad, and Z. D. Zaharis, "Direct and external intensity modulation in OFDM RoF links," IEEE Photonics Journal, vol. 7, no. 4, pp. 1-10, 2015.

[25] G. Qi, J. Yao, J. Seregelyi, S. Paquet, and C. Belisle, "Optical generation and distribution of continuously tunable millimeter-wave signals using an optical phase modulator," Journal of Lightwave Technology, vol. 23, no. 9, pp. 2687-2695, 2005.

[26] P. Mekbungwan, U. Mankong, K. Inagaki, and T. Kawanishi, "Phase-balanced differential vector modulation by laser and electroabsorption modulator," in Proceedings of the 2017 International Topical Meeting on Microwave Photonics (MWP), pp. 1-4, IEEE, Beijing, China, October 2017.

[27] G. Qi, J. P. Yao, J. Seregelyi, S. Paquet, and C. Bélisle, "Generation and distribution of a wide-band continuously tunable millimeter-wave signal with an optical external modulation technique," IEEE Transactions on Microwave Theory and Techniques, vol. 53, no. 10, pp. 3090-3097, 2005.

[28] W. Jiang, "Simultaneous generation and transmission of 60$\mathrm{GHz} \mathrm{RF}$ and baseband signals employing only a simple single 
electrode MZM," in Proceedings of the 2009 35th European Conference on Optical Communication, pp. 1-2, IEEE, Vienna, Austria, September 2009.

[29] G. H. Nguyen, B. Cabon, and Y. Le Guennec, "Generation of 60-GHz MB-OFDM signal-over-fiber by up-conversion using cascaded external modulators," Journal of Lightwave Technology, vol. 27, no. 11, pp. 1496-1502, 2009.

[30] C.-T. Lin, P.-T. Shih, W.-J. Jiang, E.-Z. Wong, J. J. Chen, and S. Chi, "Photonic vector signal generation at microwave/ millimeter-wave bands employing an optical frequency quadrupling scheme," Optics Letters, vol. 34, no. 14, pp. 2171-2173, 2009.

[31] X. Feng, P. Yang, L. He, F. Niu, B. Zhong, and H. Xu, "Heterodyne system for measuring frequency response of photodetectors in ultrasonic applications," IEEE Photonics Technology Letters, vol. 28, no. 12, pp. 1360-1362, 2016.

[32] N. H. Zhu, B. H. Zhang, J. M. Wen et al., "Analysis of the additional modulation of semiconductor lasers using optical heterodyne techniques," IEEE Photonics Technology Letters, vol. 20, no. 2, pp. 138-140, 2008.

[33] T. Kuri and K. Kitayama, "Optical heterodyne detection technique for densely multiplexed millimeter-wave-band radio-on-fiber systems," Journal of Lightwave Technology, vol. 21, no. 12, pp. 3167-3179, 2003.

[34] A. Bahrami, W. P. Ng, Z. Ghassemlooy, and C. Qiao, "Investigation of optical millimeter-wave and heterodyne techniques in radio-over-fibre systems," in Proceedings of the 2011 16th European Conference on Networks and Optical Communications, pp. 24-27, IEEE, Newcastle-Upon-Tyne, UK, December 2011.

[35] J. Ma, J. Yu, C. Yu, X. Xin, J. Zeng, and L. Chen, "Fiber dispersion influence on transmission of the optical millimeter-waves generated using LN-MZM intensity modulation," Journal of Lightwave Technology, vol. 25, no. 11, pp. 3244-3256, 2007.

[36] D. J. Maširević, T. K. Pogány, Á. Bariez, and A. Galántai, "Sampling bessel functions and bessel sampling," in Proceedings of the 2013 IEEE 8th International Symposium on Applied Computational Intelligence and Informatics (SACI), pp. 79-84, IEEE, Timisoara, Romania, May 2013.

[37] K. Noguchi, O. Mitomi, and H. Miyazawa, "Millimeter-wave Ti:LiNbO/sub 3/optical modulators," Journal of Lightwave Technology, vol. 16, no. 4, pp. 615-619, 1998.

[38] T. A. Chowdhury, M. M. A. Ghuri, and R. Kibria, "Millimeter wave generation based on optical frequency multiplication in radio over fiber systems," in Proceedings of the 2016 9th International Conference on Electrical and Computer Engineering (ICECE), pp. 94-97, IEEE, Dhaka, Bangladesh, December 2016.

[39] W. Jiang, C. Lin, H. Huang, P. Shih, J. Chen, and S. Chi, "60$\mathrm{GHz}$ photonic vector signal generation employing frequency quadrupling scheme for radio-over-fiber link," in Proceedings of the 2009 Conference on Optical Fiber Communication-Incudes Post Deadline Papers, pp. 1-3, IEEE, San Diego, CA, USA, March 2009.

[40] T.-L. Tsai and J.-C. Wu, "Low-complexity and high-flexibility design of a wavelength-selective switch using Raman amplifiers and directional couplers," Journal of Lightwave Technology, vol. 26, no. 10, pp. 1226-1233, 2008.

[41] H. G. Bassiouny and M. H. Aly, "Optical frequency multiplication for up-converting frequencies of RF signals for radio over fiber applications," in Proceedings of the 2009 IFIP International Conference on Wireless and Optical Communications Networks, pp. 1-5, IEEE, Cairo, Egypt, April 2009.
[42] S. Das, P. Dutta, and S. K. Ghorai, "Design of an RoF downlink system for generation of dual frequency millimetre wave carrier signal by frequency multiplication," in Proceedings of the 2016 2nd International Conference on Applied and Theoretical Computing and Communication Technology (iCATccT), pp. 363-367, IEEE, Bangalore, India, July 2016.

[43] X. Li, Y. Xu, J. Xiao, and J. Yu, "W-band millimeter-wave vector signal generation based on precoding-assisted random photonic frequency tripling scheme enabled by phase modulator," IEEE Photonics Journal, vol. 8, no. 2, pp. 1-10, 2016.

[44] Z. Gao, X. Wang, N. Kataoka, and N. Wada, "Time domain SPE/SPD and DPSK data modulation using single phase modulator," in Proceedings of the CLEO/QELS: 2010 Laser Science to Photonic Applications, pp. 1-2, IEEE, San Jose, CA, USA, May 2010.

[45] H. C. Chien, Y. T. Hsueh, A. Chowdhury, and G. K. Chang, "A novel carrier-eliminated optical millimeter-wave generation using a single over-driven phase modulator," in Proceedings of the 2010 Conference on Optical Fiber Communication (OFC/NFOEC), IEEE, San Diego, CA, USA, March 2010.

[46] Ye Zhang, "Photonic DPASK/QAM signal generation at microwave/millimeter-wave band for radio-over-fiber applications," in Proceedings of the 2008 International Topical Meeting on Microwave Photonics Jointly Held with the 2008 Asia-Pacific Microwave Photonics Conference, pp. 121-123, IEEE, Gold Coast, Australia, September 2008.

[47] Q. Lv, K. Xu, Y. Dai, Y. Li, J. Wu, and J. Lin, "A novel simple RF-to-digital photonic link based on a single phase modulator," in Proceedings of the 2011 International Conference on Information Photonics and Optical Communications, pp. 1-3, IEEE, Jurong West, Singapore, October 2011.

[48] P. Wu and J. Ma, "BPSK optical mm-wave signal generation by septupling frequency via a single optical phase modulator," Optics Communications, vol. 374, pp. 69-74, 2016.

[49] J. Ma, "Dual-tone QPSK optical millimeter-wave signal generation by frequency nonupling the RF signal without phase precoding," IEEE Photonics Journal, vol. 8, no. 4, pp. 1-7, 2016.

[50] R. Li, W. Li, X. Chen, and J. Yao, "Millimeter-wave vector signal generation based on a Bi-directional use of a polarization modulator in a sagnac loop," Journal of Lightwave Technology, vol. 33, no. 1, pp. 251-257, 2015.

[51] M. Zhu, J. Zhang, S. Hu et al., "Complexity reduction with a simplified MIMO volterra filter for PDM-twin-SSB PAM-4 transmission," Journal of Lightwave Technology, vol. 38, no. 4, pp. 769-776, 2020.

[52] H.-T. Huang, "Direct-detection PDM-OFDM RoF system for $60-\mathrm{GHz}$ wireless MIMO transmission without polarization tracking," in Proceedings of the 2015 Optical Fiber Communications Conference and Exhibition (OFC), pp. 1-3, IEEE, Los Angeles, CA, USA, March 2015.

[53] R. Ryf, R.-J. Essiambre, S. Randel et al., "MIMO-based crosstalk suppression in spatially multiplexed $3 \times 56-\mathrm{Gb} / \mathrm{s}$ PDM-QPSK signals for strongly coupled three-core fiber," IEEE Photonics Technology Letters, vol. 23, no. 20, pp. 14691471, 2011.

[54] K. Takeshima, H. Takahashi, I. Morita, and H. Tanaka, "Polarization demultiplexing using linearly interpolated channel matrix in PDM systems with MIMO processing," in Proceedings of the 16th Opto-Electronics and Communications Conference, pp. 419-420, IEEE, Kaohsiung, Taiwan, July 2011.

[55] S. Randel, "MIMO-based signal processing of spatially multiplexed 112-Gb/s PDM-QPSK signals using strongly-coupled 
3-core fiber," in Proceedings of the 2011 37th European Conference and Exhibition on Optical Communication, pp. 1-3, IEEE, Geneva, Switzerland, September 2011.

[56] Y. Zhao, "Experimental demonstration of $5-\mathrm{Gb} / \mathrm{s}$ polarization-multiplexed fiber-wireless MIMO systems," in Proceedings of the 2011 International Topical Meeting on Microwave Photonics Jointly Held with the 2011 Asia-Pacific Microwave Photonics Conference, pp. 13-16, IEEE, Singapore, Singapore, October 2011.

[57] M. Morsy-Osman, M. Chagnon, M. Poulin, S. Lessard, and D. V. Plant, "224-Gb/s 10-km transmission of PDM PAM-4 at $1.3 \mu \mathrm{m}$ using a single intensity-modulated laser and a directdetection MIMO DSP-based receiver," Journal of Lightwave Technology, vol. 33, no. 7, pp. 1417-1424, 2015.

[58] M. F. Panhwar, D. Sandel, C. Woerdehoff, S. Hussin, and R. Noe, "PU-CMA-QAM based MIMO equalization for digital PMD compensation in PDM-16-QAM receivers," in Proceedings of the Photonic Networks; 15. ITG Symposium, pp. 1-4, IEEE, Leipzig, Germany, May 2014.

[59] A. Aimone, F. Frey, and R. Elschner, "DAC-less 32-GBd PDM-256-QAM using low-power InP IQ segmented MZM," IEEE Photonics Technology Letters, vol. 29, no. 2, pp. 221-223, 2017.

[60] B. Prasad, B. Mallick, K. C. Patra, and N. K. Barpanda, "Dsp based chromatic dispersion equalization techniques in PDMQPSK receivers," in Proceedings of the 2019 3rd International Conference on Trends in Electronics and Informatics (ICOEI), pp. 302-307, IEEE, Tirunelveli, India, April 2019.

[61] C. Mateo, P. L. Carro, P. Garcia-Ducar, J. de Mingo, and I. Salinas, "RoF spatialMux MIMO-LTE fronthaul system transmission parameter selection with nelder-mead optimization algorithm," in Proceedings of the 2018 IEEE/MTT-S International Microwave Symposium-IMS, pp. 1046-1049, IEEE, Philadelphia, PA, USA, June 2018.

[62] M. Noweir, A. Abdelhafiz, M. Helaoui, F. M. Ghannouchi, and D. Oblak, "Low speed digital RoF transmitter linearizer using sub-band signal processing technique," in Proceedings of the 2019 IEEE MTT-S International Wireless Symposium (IWS), pp. 1-3, IEEE, Guangzhou, China, May 2019.

[63] D. Wang, X. Chen, L. Wang, and M. Zhu, "Study of the ROF system based wavelength interleaving and double sideband modulation with carrier suppressed," in Proceedings of the 2016 2nd IEEE International Conference on Computer and Communications (ICCC), pp. 2134-2138, IEEE, Chengdu, China, October 2016.

[64] V. Sharma and J. Kaur, "Modeling of radio over fiber (RoF) system incorporating multi-carrier multiplexing," in Proceedings of the 2016 International Conference on Computing, Communication and Automation (ICCCA), pp. 1338-1341, IEEE, Noida, India, April 2016.

[65] A. T. Latunde, M. Milosavljevic, P. Kourtessis, and J. Senior, "OQAM-OFDM RoF with IM-DD remote heterodyne 28 $\mathrm{GHz}$ upconversion for $5 \mathrm{G}$ millimeter RANs," in Proceedings of the 2016 18th International Conference on Transparent Optical Networks (ICTON), pp. 1-4, IEEE, Trento, Italy, July 2016.

[66] Y. J. Cheng, K. Wu, W. Hong, and X. W. Zhu, "Millimeterwave reconfigurable antenna with polarization and angle diversity," in Proceedings of the 2009 IEEE Radio and Wireless Symposium, pp. 300-303, IEEE, San Diego, CA, USA, January 2009.

[67] J. A. G. Akkermans and M. H. A. J. Herben, "Millimeter-wave antenna with adjustable polarization," IEEE Antennas and Wireless Propagation Letters, vol. 7, pp. 539-542, 2008.
[68] H. Kishikawa, N. Goto, and L. R. Chen, "All-optical wavelength preserved modulation format conversion from PDMQPSK to PDM-BPSK using FWM and interference," Journal of Lightwave Technology, vol. 34, no. 23, pp. 5505-5515, 2016. 